\title{
HOUSEHOLD AND SACRED USE OF THE POTTERY BY THE SARMATIAN TRIBES OF THE SOUTHERN URALS AND WESTERN KAZAKHSTAN
}

(C) 2015

\author{
L.A.Kraeva, candidate of Historical Sciences \\ Orenburg state pedagogical university, Orenburg (Russia)
}

\begin{abstract}
The article deals with the pottery from the Sarmatian burial grounds of the Southern Urals and Western Kazakhstan. Pottery was placed in the graves of the representatives of all social stratums of the nomadic population. In more expensive imported dishes were usually placed. Sarmatian ceramics was actively used both in household and in religious ceremonies. Specially produced vessels for burial rites are found in the graves, as well as utensils already used in the household, including those repaired. The author points out the signs which prove that the pottery had been in household use before being placed in the grave: the presence of soot on the inner and outer walls of the vessels; grease stains and traces of boiling over liquid food; repair marks; (broken handles, chipped edges of the vessels, etc.); scuff marks and homemade polishing; the change of color on the surface the vessel and on the layers of the potsherds. The characteristics proving that the pottery was specially manufactured burial rites include: the use of raw materials with rough natural impurities; poor quality battering (uneven distribution of tempers); negligence in the moulding; short-term exposure to temperatures below $450{ }^{\circ} \mathrm{C}$ during firing;) the absence of soot on the walls of the vessel; the absence of repair marks.

The examination of the surface of the vessels and experimental work let the author make an assumption about the functional use of some types of pottery.

Keywords: pottery; sarmatians; Southern Urals; Western Kazakhstan; vessels specially prepared for the burial rite; household use; sacred use.
\end{abstract}

\section{УДК 902 \\ ПЕТРОГРАФИЧЕСКИЙ АНАЛИЗ В ОЦЕНКЕ ФОРМОВОЧНЫХ МАСС ПРИ ИЗУЧЕНИИ ДРЕВНЕЙ ГЛИНЯНОЙ ПОСУДЫ}

(C) 2015
M.A. Кулькова, кандидат геолого-минералогических наук, доцент кафедры геологии и геоэкологии Российский государственный педагогический университет им. А.И. Гериена, Санкт-Петербург (Россия)

\begin{abstract}
Аннотацุия. В статье рассматривается ряд вопросов, касающихся петрографического метода исследования древней керамики. На основе литературных данных обсуждаются различные характеристики древней керамики по данным петрографического анализа, которые дают возможность оценить источники сырья, состав керамического теста, условия и температуру обжига и, в конечном счете, понять технологический процесс изготовления древней посуды, а также установить различия в традициях изготовления керамики и появление импортных изделий. Процесс изготовления глиняного сосуда начинается с выбора и подготовки глиняного теста (глины и отощителя) и продолжается через последовательность различных техник (формовки сосуда, обработки поверхности) и наконец, обжига. В шлифах могут быть определены различные характеристики керамического материала: природа и характеристики непластичных включений (минеральный состав, процентное содержание, размеры, форма, распределение и ориентация отдельных частиц); текстурные и оптические характеристики глинистой матрицы (двулучепреломление, цвет); форма, количество и ориентация пустот; особенности обработки поверхности, декорация. Информация, полученная по петрографии о керамической структуре и материалам, используемым для создания глиняного изделия, позволяет выяснить принципы, которые гончар применял для выбора и переработки глинистого сырья, лепки сосуда, условий обжига и создания окончательного изделия. Понимание природы этих процессов может быть важным для нашего знания о прошлом, особенно в отношении источников минерального сырья, пространственного распределения торговых связей, специализации производственных технологий и развития технологий.

Ключевые слова: петрография; древняя керамика; шамот; отощитель; источники сырья; составы формовочных масс.
\end{abstract}

\section{Введение}

Керамика является важным артефактом, которая сохранила информацию о древних сообществах. Форма и декоративные детали глиняного сосуда представляют собой конечную фазу в комплексе технологической цепочки [1]. Процесс изготовления глиняного сосуда начинается с выбора и подготовки глиняного теста (глины и отощителя) и продолжается через последовательность различных техник (формовки сосуда, обработки поверхности) и наконец, 
обжига. Стандартный типологический анализ сосуда предполагает, что первоначальная цель гончара была придать продукции определенную форму, которая была установлена сознательно или несознательно культурными традициями. С этой точки зрения, сосуды могли выполнять определенную функцию внутри сообщества, были ли эти сосуды утилитарными или престижными, и изменения в стиле, по-видимому, отражали изменения в обществе, такие как его взаимодействие с другими сообществами или влияние окружающей природной среды [2]. Любая стадия в индустриальной последовательности может оказывать влияние на следующую стадию в этой самой последовательности.

Применение современных аналитических методов для изучения древней керамики дает возможность количественно установить минеральный и химический составы формовочной массы, выявить технологические приемы изготовления, идентифицировать источники сырья [3, 4, 5]. Эти данные расширяют знания о древнем керамическом производстве и дают представление о технологических традициях в изготовлении керамики, что позволяет по-новому взглянуть на археологические комплексы, выявленные лишь на основе типологических и морфологических характеристик керамики.

История развития метода петрографических исследований древней керамики.

Петрографический метод стал широко применяться для изучения керамики после появления исследований, которые проводила А.О. Шепард в XX в. В 1942 г. она опубликовала результаты по петрографическому анализу глазурированной расписной керамики Рио Гранде, которая была найдена при археологических раскопках Пекоса (1300-1830 гг. н.э.) в Нью Мехико. На основании технологических особенностей изготовления керамики, а именно различия в типах отощителя, которые были определены при петрографическом исследовании, А.Шепард выделила несколько различных типов керамики, а также определила географическое местоположение источников сырья, которые были использованы для изготовления керамики. Важность изучения древней керамики с помощью метода петрографического исследования А.Шепард отразила в своей монографии «Керамика для археологов» [6].

Некоторые особенности древнего гончарства были отражены американцем Фредериком Р.Мэтсоном в работе «Гончарство» [7]. Автор делает вывод, что изучение древней керамики с помощью морфологического и стилистического анализов глиняной посуды, является не достаточным для того, чтобы понять древние культуры. Исследователи должны изучать также технологические процессы и источники минерального сырья, которые использовались для создания керамической посуды для того, чтобы понять роль гончара и его продукции в древнем сообществе. Мэтсон также указал на то, что большую роль в понимании источников сырья, из которых были изготовлены изделия, является анализ образцов отложений, которые могли применяться в качестве глинистого сырья и отощителя. Его теоретические основы, в конце концов, легли в основу научного направления - керамической экологии, представляющей собой мультидисциплинарный подход к изучению древних керамических технологий, целью которого является понять влияние культуры на создание керамических материалов. Керамическая петрология становится популярной в Европе в 1960-х годах в связи с работами Д.Пикока в Великобритании [8, $9,10]$. Пикок опубликовал результаты своей работы по изучению керамики из Херефордшир-Котсволд в западной Англии. Исследуя минеральный состав образцов, Пикок сделал вывод, что две выделенные группы керамики были изготовлены из местного материала, а различия в орнаментации могут объясняться тем, что они были сделаны в разных производственных центрах. При изучении римской керамики из Фишбурна, Пикок применил текстурный анализ. В качестве отощителя для изготовления этой керамики использовался песок, и были изучены сферичность, окатанность, процентное содержание и размер отдельных кварцевых песчаных зерен. Это исследование позволило по морфологическим особенностям отдельных кварцевых зерен определить локальные и импортные источники отощителя. И хотя, Пикок был не первым исследователем, кто применял текстурный анализ в петрографии, он смог продемонстрировать его ценность для изучения древней керамики. Дальнейшее развитие петрографии приводит к тому, что в настоящее время петрография керамики становиться неотъемлемым компонентом при современном изучении древних гончарных технологий, как за рубежом, так и в России.

Характеристики древней керамики по данным петрографического анализа.

Петрография древних керамических изделий является одной из ценных аналитических техник для современного изучения керамики. Она применяется для определения структуры глинистых материалов, исследуя ее в тонких срезах под микроскопом. Различные материалы и их характеристики можно отличить на основании деталей микроструктуры, которая не может быть определена визуально или при увеличении с помощью оптического микроскопа. Петрографическое исследование позволяет определить структурные детали, которые при применении обычного микроскопа могли быть упущены из виду или неправильно интерпретированы. Главная цель петрографического исследования керамики охарактеризовать структуру и материал изделий из глины в тонком керамическом срезе - шлифе под поляризационным микроскопом. Этот тип микроскопа пропускает поляризационный свет через тонкий срез керамики, что позволяет оценить два главных компонента керамики - пластичную (глинистую) составляющую и непластичную составляющую. Кроме того, важной характеристикой керамики является оценка степени пористости, размер, форма пор и информация об обработке поверхности. Внешний вид и технические 
свойства конечного продукта определяются этими характеристиками. Петрографическое исследование позволяет на основе представленных данных сделать выводы о технологических особенностях изготовления керамики и источниках минерального сырья.

В шлифах могут быть определены следующие характеристики керамического материала [11]:

1. Природа и характеристики непластичных включений (минеральный состав, процентное содержание, размеры, форма, распределение и ориентация отдельных частиц).

2. Текстурные и оптические характеристики глинистой матрицы (двулучепреломление, цвет).

3. Форма, количество и ориентация пустот.

4. Особенности обработки поверхности, декорация.

Изучение этих особенностей позволяет лучше понять технологию изготовления керамики в прошлом. Информация, полученная с помощью петрографии по керамической структуре и материалам, используемым для создания глиняного изделия, позволяет выяснить принципы, которые гончар применял для выбора и переработки глинистого сырья, лепки сосуда, условий обжига и создания окончательного изделия. Понимание природы этих процессов может быть важным для нашего знания о прошлом, особенно в отношении источников минерального сырья, пространственного распределения торговых связей, специализации производственных технологий и развития технологи.

В петрографических исследованиях керамики одним из ключевых вопросов является оценка характеристик непластических включений, пластических включений и пористости. Характеристика непластических включений - одна из основных характеристик древней керамики. Эти включения часто называются грубой фракцией и могут присутствовать в природных глинах. Они также могут искусственно вводиться в глинистую массу, для того, чтобы уменьшить пластичность керамического теста, повысить его рабочие характеристики, уменьшить неблагоприятные эффекты, такие как растрескивание при расширении, увеличение термального сопротивления в период нагрева и укрепление керамического тела, как конечного продукта [12]. Некоторые типы непластического материала можно различать в шлифах:

1. Минеральные включения дробленых кристаллических пород.

2. Органические включения (растительные материалы, раковины, кости).

3. Шамот.

Минералы, как правило, в непластичных включениях под поляризованным микроскопом можно легко и точно определить. Они характеризуются определенными оптическими свойствами в поляризованном и проходящем свете, включающие прозрачность, цвет, морфологию, двулучепреломление, изотропизм или анизотропизм. В большинстве случаях можно определить являлись ли непластичные включения природными или были добавлены искусственно, как отощитель $[13,14]$. Процентное содержание вклю- чений, состав, размер зерен, форма, распределение в керамической массе показывает это. Непластические включения перед добавлением в керамическую пасту могут быть предварительно растерты или раскрошены, кроме того, предварительно также могут быть декантированы или отделены от других включений. Большинство органических включений могут быть определены по наличию углеродных включений, которые остаются при неполном выгорании органики или по порам, оставшимся после полного выгорания органических включений. Такие добавки, как уголь, кокс, зола, пепел, органические и домашние отходы, шлак, солома, мел, пыль, песок, дробленая порода, шамот (обожженные остатки дробленой керамики или обожженная и растертая глина), меласса, пигмент и т. д., могут быть добавлены в глину для различных целей. Например, добавление к глине песка, дресвы или шамота предотвращает растрескивание изделия в процессе сушки и обжига. Одной из проблем является определение искусственной примеси мелкозернистого песка или алеврита (размером около 0,25 мм), которые могли использоваться в качестве отощителя. Если в виде отощителя использовался алеврит, то обычно размер зерен калиброванный, они имеют определенную размерность, часто хорошей окатанности и зерна очень хорошо отличаются от зерен кластической составляющей, обычно более мелкозернистой и неравномерно-зернистой. Если отощитель в виде алеврита не используется, а применяется глина с естественной алевритовой составляющей, то алеврит или мелкозернистый песок имеют неравномернозернистый характер, различную размерность, некалиброванные. Для этих образцов также характерно, что алеврит плохо распределен в тесте, встречаются участки с более крупными зернами и средними или мелкими зернами. В случае применения алеврита, в качестве отощителя, зерна распределены более или менее равномерно, нет скоплений крупных и мелких зерен. Кроме того, можно проследить линейное распределение зерен по лентам при ленточном способе лепки. Как отмечает Глушков И.Г. [15], только сочетание самых различных вариантов признаков делает вывод о характере добавок корректным и уменьшает вероятность ошибочного заключения. Например, об искусственности песка свидетельствует прежде всего его гранулометрический состав: характер концентрации в поле шлифа - неокатанная преобладающая фракция размером $>0,25$ мм равномерно распределенная, с большей вероятностью будет свидетельствовать об искусственном характере песка. Вероятность естественного характера песка повышается, если степень окатанности крупных фракций минимальна или совсем отсутствует. Кроме того, в пользу естественного характера песка свидетельствует нормальное распределение частиц в графике или гистограмме, указывающее на равновероятное присутствие всех гранулометрических групп с явным преобладанием одной или нескольких из них. По данным исследователей, которые занимались экспериментальным изучением состава керамики в зависимости от тем- 
пературы обжига [16] было установлено, что предел прочности керамики уменьшается, если используются частицы от 100 мкм до 750 мкм. Т.е. чем более мелкозернистый песок используется, тем трещиноватость меньше. Поэтому, в большинстве случаев, древние гончары предпочитают использовать в качестве отощителя алеврит, а не песок.

Уголь, пепел, зола добавляются в глины, как это сложилось исторически, для того, чтобы улучшить процесс обжига керамики и поднять ее температуру [17].

Термин «шамот» был определен вслед за А.Шепард [6], Райсом [13] как предварительно обожженный глинистый продукт, растертый в мелкие кусочки и добавленный в глину как отощитель. Такое определение шамота также относится и к высушенной глине [18]. Как отмечают А.В.Гребенщиков и Е.И.Деревянко [19], традиционно шамотом исследователи считают: 1) обожженную измельченную глину; 2) дробленый керамический черепок; 3) высушенную комковатую глину; 4) непластичную, неразмокающую в водое глинистую породу (сухари, флинткели). Рыхлый комковатый шамот мог приготавливаться способом, близким тому, который описан в литературе Е.Уивер: за время формовки сырец высыхал настолько, что покрывался корочкой; ее в дальнейшем разминали, а получившуюся сухую крошку добавляли в следующую порцию глиняного теста. Чаще всего в глиняной посуде Приамурья встречаются единичные зерна шамота, составляющие около 5\% объема всего шлифа, иногда количество отощителя увеличивается до 5-10\% и редко до 10-20\%. Размер зерен шамота 1,5-2 мм. Н.Н. Дубицкая [20] также выделяет различные типы шамота в тесте глиняной посуды киевской культуры. По сравнению с глинистым веществом основной массы, глинистое вещество частиц керамического отощителя в большинстве случаев аморфизовано гораздо сильнее, иногда почти полностью, что предполагает их двойной обжиг. Это свидетельствует о том, что исходным материалом для получения шамота служил измельченный посудный бой или другие обожженные отходы керамического производства. Однако встречаются включения, в которых степень аморфизации глинистого вещества лишь немногим больше или адекватна аморфизации вмещающей массы. Поэтому есть основание выделить несколько видов материала для получения шамота: 1) отходы керамического производства в виде боя посуды, 2) обожженная глина или формовочная масса, 3) высушенная глина (формовочная масса). По степени спекания шамот можно подразделить на высокотемпературный и низкотемпературный. Широкое использование подсушенной растертой глины (шамота) в качестве отощителя отмечено Сайко [21] для глиняной посуды трипольской культуры. При низкотемпературном обжиге введение такого материала обеспечивало разное, но практически одновременное температурное преобразование масс отощителя и глиняного теста. Включения необожженной сухой глины подвергались изменениям одновременно с массой черепка и поэтому являлись мягким и пластичным отощителем. Зерна шамота (в данном случае автор объединяет под этим названием все виды имеющего глинистую природу отощителя, исключая глинистый сланец) имеют в глиняных массах трипольских изделий разную форму, пористость, размер, процентное содержание. Зерна высушенной комковатой глины в шлифах под поляризационным микроскопом отличаются от железистых оолитов, которые могут встречаться в илистых и глинистых отложениях. Образование железистых оолитов происходит в природе из коллоидных растворов. Существуют две основных концепции об образовании железистых оолитов: 1) оолитообразование происходило в процессе седиментации в гидродинамически активной среде в наддонной воде или в поверхностном слое жидкого ила при чередующейся адсорбции разнозаряженных частиц вокруг какого-либо центра (пузырек воздуха, обломочные частицы, коллоидные сгустки), что приводило к образованию концентрического строения; 2) оолиты образовались в спокойной гидродинамической обстановке в процессе диагенеза при одновременном осаждении комплексных коллоидов и их раскристаллизации. В процессе образования оолитов происходит последовательное нарастание вокруг ядра тонких корочек осаждающегося вещества. Размеры оолитов от нескольких км до 15-25 мм [22]. В шлифах железистые оолиты имеют концентрически-зональное строение, в центре овоидов, как правило, можно различить зерно минерала, вокруг которого происходило нарастание железистых корочек. В отличие от оолитов, высушенные комочки глины не имеют такого строения и изотропны в поляризационном свете. Они также отличаются от включений гематита в глинах, который в тонких пластинках просвечивает густо красным цветом, имеет оптические характеристики: оптически отрицательный. $\mathrm{Nm}=3.01, \mathrm{~Np}=2.78$ [23]. Высушенные комковатые кусочки глины могли также оставаться в глиняном сырье в процессе его подготовки. Как отмечает О.Рей $[1,24]$, простейший технологический уровень подготовки глинистого сырья, когда глина полностью высушивается на солнце и крошится на небольшие кусочки, таким образом, что нежелательные включения могут быть выбраны руками. Более сложным способом удаления грубых частиц является ситование. В процессе такой первичной подготовки высушенные плотные кусочки глины могли оставаться в тесте после его промеса.

Пластичное вещество в керамике представляет собой, как правило, глинистую матрицу. Глинистая матрица в керамических изделиях, главным образом, состоит из глинистых минералов и других минеральных зерен, размер которых меньше 2 микрон в диаметре. Глинистые минералы являются главным компонентом глинистого теста, которые способствуют его пластичности, т. к. тонкие, листоватые агрегаты глинистых минералов способны абсорбировать молекулы воды на своей поверхности. Кристаллы глинистых минералов неопределимы под микроскопом, несмотря на это, различные типы глин могут быть различимы по их оптическим характеристикам, анизотропности 
или изотропности и двулучепреломлению [25]. При высоких температурах обжига глинистые минералы становятся стекловатыми, формируя шпинель или стекло, которые изотропны в скрещенных николях.

Условия обжига керамики по данным петрографии.

Керамическая структура может также давать информацию об условиях обжига. По некоторым данным [17] открытый огонь характеризуется быстрой скоростью нагрева и очень коротким временем максимальных температур. Максимальные температуры достигаются от 500 до $900^{\circ} \mathrm{C}$ с большой вероятностью диапазона 600-800оС. Характеристики изменений различных минералов в керамическом тесте при нагревании в процессе обжига были рассмотрены рядом исследователей $[13,26,27,28]$. Было выявлено, что минералы карбонатов разлагаются при температурах $700-800^{\circ} \mathrm{C}$. Когда происходит нагрев при температуре выше $750^{\circ} \mathrm{C}$ карбонат кальция начинает разрушаться на $\mathrm{CO} 2$ и $\mathrm{CaO}$. Кварц подвергается кристаллической инверсии при $573^{\circ} \mathrm{C}$, изменяет свою молекулярную структуру и увеличивает размер кристаллов, это проявляется в растрескивании зерен [1]. Около $400^{\circ} \mathrm{C}$ начинается постепенное выгорание углерода, которое может происходить как в окислительный, так и в восстановительной средах. Одновременно происходит пирогенетическое разложение гумусовых веществ. Это разложение сопровождается науглероживанием черепка. Выгорание углерода из черепка резко усиливается при 700-800 C [29]. Определение температуры обжига керамики по минералогическим характеристикам было рассмотрено в работе И.С.Жущиховской, Б.Л.Залищак [30]. При $800^{\circ} \mathrm{C}$ начинают разрушаться каолинит и кальцит в глинах, богатых известью, могут появиться новообразования геленита. При $850^{\circ} \mathrm{C}$ начинают изменяться гидрослюды, могут появиться образования волластонита в глинах, богатых известью. При $870^{\circ} \mathrm{C}$ при длительном нагревании, начиная с этой температуры и выше, по краям и трещинам кварцевых зерен наблюдается образование кристобалита, однако полного замещения кварца не происходит даже при $1650^{\circ} \mathrm{C}$.

Керамическая матрица также содержит поры или овоиды, которые можно зафиксировать в шлифах. Количество, форма и размеры пор отражают условия их образования. Образование пор возможно в результате выгорания органики, освобождения газов или при растрескивании глинистой матрицы в период сушки или обжига [31]. На объем порового пространства внутри матрицы, также как и на размеры пор и их форму могли влиять плотность, прочность, проницаемость, термальная устойчивость керамического материала [6]. Так, присутствие отдельных зерен с ясными контактами, матрицы с двупреломлением и высокая пористость являются признаками низких температур обжига. Наоборот, значительная степень соединений между зернами, опаковая матица с минеральной сегрегацией, присутствие минеральных преобразований, растрескивание зерен, уменьшение пористости является признаком повышенных темпе- ратур обжига, которые показывают, что керамическое тело начинает спекаться, происходит остеклование. Условия обжига или атмосфера может быть установлена по цвету черепка. Красная, до красно-оранжевого цвета окраска предполагает окислительные условия с большим содержанием кислорода, в то время как окраска от темно-коричневого до темно-красно-черного до черного (или черно-серый) свидетельствует об уменьшении кислорода и преобладании восстановительных условий [31].

Петрографический анализ дает возможность понять технологический процесс изготовления керамики [11], включающий определение местного или импортного производства, методы подготовки сырья, такие, как ситование, смешивание с водой, перемешивание с отощителем и обжиг. Некоторые особенности глинистого сырья, такие как его жирность, включения песка, алеврита, гравия или органики информируют не только о возможном происхождении глинистого сырья, но также о тех типах отложений, которые были использованы для изготовления керамики и их влиянии на физические особенности глиняных изделий.

Исследование керамики в шлифах также может дать информацию о том, каким способом поверхность керамики была обработана. И наоборот, эти аспекты позволяют взглянуть на технологию производства и разработку стилистического тренда. Поверхностная обработка может служить индикатором используемых материалов, цвета, условий обжига, толщины глазури, поливы, окраски, эмали [25].

Изменения в распределении глинистых частиц в керамической матрице, в отличие от непластичных включений, может дать информацию о методах формовки [31].

Оценка выбора сырья для изготовления глиняной посуды.

Несмотря на то, что в настоящее время существует большое количество литературы, описывающей процесс изготовления современной керамики, очень мало информации о составе теста и его поведении в процессе технологических операций. Основополагающие труды в этом направлении, включающие произведения А.Шепард [6], руководство по керамической технологии Рея [1] и энциклопедия по керамическим технологиям Райса [13] описывают этнографические детали о процессах выбора сырья и подготовке теста. Некоторые исследования описывают критерии выбора минерального сырья по этнографическим данным [32, $33,34,35,36,37,38,24,39]$. Намного меньше известно о социальном контексте выбора минеральных источников сырья и снабжения [40, 41, 38, 42]. Тем не менее, одним из главных факторов в выборе сырья являются геологические условия региона и условия доступности подходящего сырья. По данным, Бишопа и др. [43] было определено пять стратегий для выбора керамического сырья: (1) использование в равной степени доступных глиняных источников без дискриминации между ними; (2) выбор из числа одинаково доступных минеральных источников (3) использование более или менее одинаково доступных источников 
для конструирования различных типов судов; (4) смешивание минеральных источников для достижения конкретных свойств теста; (5) использование более отдаленных источников, которые характеризуются более высокими качествами. По этно-археологическим данным были выделены некоторые природные и культурные факторы, которые являются основополагающими для выбора сырья и изменчивости состава рецептуры теста. Они включают в себя химические и минералогические изменения глинистого сырья в результате геологических и географических процессов и целый ряд факторов, которые отражают выбор решений гончаров (связанных с деятельностью в процессе производства и использования готовых изделий, а также изменения численности населения), контроль за ресурсами и ограничениями к сырьевому доступу и т. д. Эти характеристики могут быть установлены при изучении петрографического состава набора керамики, принадлежащей к одной и той же культуре и из одного региона. Результаты петрографического анализа статистически значимой выборки образцов дают возможность оценить критерии выбора сырьевых ресурсов для изготовления глиняной посуды, а также оценить наличие импортных изделий.

\section{Заключение}

Петрографические исследования позволяют выявить минеральный состав формовочной массы, идентифицировать естественные и искусственные добавки и определить их количество, изучить текстурные особенности керамики. По композиционному составу глин и отощителей можно выделить рецептуры керамического теста и предположить источники минерального сырья, тогда как температурные характеристики и условия среды обжига позволяют охарактеризовать использованные технологические приемы.

\section{СПИСОК ЛИТЕРАТУРЫ}

1. Rye O.S. Pottery Thechnology. Priciples and recontruction. Manuals on archaeology. Owen. Taraxacum, Wahington, 1981. 148p.

2. McGovern P.E. Ancient Ceramic Technology and Stylistic Changes: Contrasting Studies from Southwest and Southeast Asia. Scientific Analysis In Archaeology and Its Interprethtion, ed. J. Henderson. Oxford Committee for Archaeology, Monograph 19; UCLA Institute of Archaeology, Archaeological Research Tools 5. Oxford: Oxford University. 1989. P. 63-81

3. Feliu, M. J., Edreira, M. C. and Martín, J. Application of physical-chemical analytical techniques in the study of ancient ceramics. Analytica Chimica Acta, vol. 502. 2004. P. 241-250

4. Papadopoulou D.N., Lalia-Kantouri M., Kantiranis N., Stratis J.A. Thermal and mineralogical contribution to the ancient ceramics and natural clays characterization. Journal of Thermal Analysis and Calorimetry. Vol. 84, No. 1. 2006.

5. Bastie P., Hamelin B., Fiori F., Giuliani A., Giunta G., Rusti-chelli F., Gysens J. A new method based on hard $\mathrm{X}$-ray diffraction for the investigation of archaeological artifacts. Meas. Sci. Technol. Vol. 17. 2006.

6. Shepard A.O. Ceramics for archaeologists. Carnegie Inst. Washington, 1956. 414 pp.

7. Matson F.R. Pottery. Appendix in The Young site: An Archaeological record from Mechigan, by E.F. Greenman. Occasional Contributions. № 6. Ann Arbor. 1937. P. 99-124

8. Peacock, D.P.S. A Petrological Study of Certain Iron Age Pottery from Western England. Proceedings of the Prehistoric Society 34. 1968. P. 414-427.

9. Peacock D.P. S. The scientific analysis of ancient ceramics: A review. World Archaeology. Vol. 1(3). 1970. P. 375-389

10. Peacock D.P.S. Pottery of the Roman world: an ethnoarchaeological approach. Longman, London, New York. 1982.

11. Peterson S. E. Thin-section petrography of Ceramic Materials. INSTAP Archaeological Excavation Manual 2. INSTAP Academic Press Philadelphia, Pennsylvania. 2009. P. 22

12. Williams D.F. A Petrological Examination of Pottery from Thera, in Doumas, ed., 1979. P. 507-514.

13. Rice P.M. Pottery Analysis. A Sourcebook. The University of Chicago Press. Chicago and London. 1987.

14. Stoltman, J.B. A Quantitative Approach to the Petrographic Analysis of Ceramic Thin Sections. American Antiquity. 54. 1989. P.147-160.

15. Глушков И.Г. Керамика как исторический источник. Новосибирск: Издательство Института археологии и этнографии СО РАН, 1996. 328 с.

16. Tite M.S., Kilikoglou V., Vekinis G. Strength, toughness and thermal shock resistance of ancient ceramics, and their influence on thecnological choise. Archaeometry 43, 3. 2001. P. 301-324.

17. Pavia S., Caro S. Petrographic microscope investigation of mortar and ceramic technologies for the conservation of built heritage. Optics for Arts, Architecture and Archaeology. Vol. 6618. 2007.

18. Ashley K. H., Rolland V. L. Grog-tempered pottery in the Mocama Province. The Florida Anthropologist. Vol. 5, 2. 1997. P. 51-65.

19. Гребенщиков А.В., Деревянко Е.И. Гончарство древних племен Приамурья (начало эпохи раннего железа). Новосибирск: Изд-во ИАЭТ СО РАН, 2001. $120 \mathrm{c}$.

20. Дубицкая Н.Н. Керамическое производство Белорусского Поднепровья в VIII в. до н.э. - V в. н.э. Минск, 2002.

21. Сайко Э.В. Технологическая организация раннеземледельческих культур// Studia Praehistorica. София., 1982. № 7.

22. Рейхард Л.Е. Коллойдное происхождение киммерийских железных оолитовых руд Таманского полуострова // Минералогические перспективы, 2011. C. $263-264$.

23. Бетехтин А.Г. Минералогия. М.: Государственное издательство геологической литературы, 1950. $956 \mathrm{c}$.

24. Rye O. S. Keeping your temper under control: Materials and the manufacture of Papuan pottery. 
Archaeology and Physical Anthropology in Oceania 11. 1976. P.106-137.

25. Reedy C.L. Thin-Section Petrography of Stone and Ceramic Cultural Materials, Plymouth, UK, 2008.

26. Мiос̌ И. В., Colomban Ph., Sagon G., Stojanović M., Rosić A. Ochre decor and Cinnabar Residues in Neolithic Pottery from Vinča, Serbia. J. Raman Spectroscopy. 35. 2004. P.843-846.

27. Maniatis Y. From Mine to Microscope: Advances in the Study of Ancient Technology. The Emergence of Ceramic Technology and its Evolution as Revealed with the use of Scientifi c Techniques. Oxford. 2009.

28. Livingstone Smith A. Bonfire 2: The Return of Pottery Firing Temperatures. Journal of Archaeological Science. 28, no. 9, 2001. Р. 991-1003.

29. Августиник А.И. Керамика. Изд. 2-е, перераб. и доп. Л.: Стройиздат (Ленингр. отделение), 1975. 592 с.

30. Жущиховская И.С., Залищак Б.Л. Петрографический метод в изучении древней керамики (на материале неолитических средневековых культур Приморья) // Методы естественных наук в археологическом изучении древних производств на Дальнем Востоке СССР. Владивосток, 1986. С. 55-67.

31. Velde B. and Druc I.C. Archaeological Ceramic Materials, Berlin. 1999.

32. Arnold D. E. Ethnomineralogy of Ticul,Yucat'

an potters: Etics and emics. American Antiquity, 36: 1971. P. 20-40.

33. Arnold D. E. Mineralogical analyses of ceramic materials from Quinua, Department of Ayacucho, Peru. Archaeometry 14: 1972. P. 93-101

34. Arnold D. E. The Ecology of Ceramic Production in an Andean Community, Cambridge University Press, Cambridge. 1993.

35. Arnold D. E. Neff H. and Bishop R. L. Compositional analysis and sources of pottery: An ethnoarchaeological approach. American Anthropologist 93: 1991. P. 70-90.

36. Arnold D. E., Neff H., Bishop R. L. and Glascock M. D. Testing interpretative assumptions of neutron activation analysis: Contemporary pottery inYucat'an, 1964-1994. In Chilton, E. (ed.),Material Meanings: Critical Approaches to the Interpretations of Material Culture, University of Utah Press, Salt Lake City, 1999. pp. 61-84.

37. Druc I. C. De la etnograf' 1 a hac' 1a la arqueolog' $1 a$ : Aportes de entrevistas con ceramistas de Ancash (Per'u) para la caracterizaci'on de la cer'amica prehisp'anica. Bolet'in del Institut Francais d' 'Etudes Andines 25: 1996. P. 17-41.

38. Gosselain O. P. 1998. Social and technical identity in a clay crystal ball. In Stark, M. T. (ed.), The Archaeology of Social Boundaries, Smithsonian Institution Press, Washington, DC, pp. 78-106.

39. Costin C. L. The Use of Ethnoarchaeology for the Archaeological Study of Ceramic Production. Journal of Archaeological Method and Theory, Vol. 7, No. 4. 2000. P.377

40. Bowser B. J. Local and regional exchange of ceramic resources in the Ecuadorian Amazon. Paper presented in the session «Ceramic Ecology '96',» 95th Annual Meeting of the American Anthropological Association, San Francisco, CA, November 20-24, 1996.

41. DeBoer W. R. The last pottery show: System and sense in ceramic studies. Van der Leeuw, S. E., and Pritchard, A. C. (eds.), The Many Dimensions of Pottery: Ceramics in Archaeology and Anthropology, Universiteit van Amsterdam, Albert Egges van Giffen Instituut voor Prae- en Protohistorie, Cingula VII, Amsterdam. 1984.

42. Neupert M. Factionalism and clay composition: An ethnoarchaeological example. Journal of Archaeological Method and Theory. V. 7(3). 2000. P.249-272

43. Bishop R. L., Rands R. L., and Holley G. R. Ceramic compositional analysis in archaeological perspective. In Schiffer, M. B. (ed.), Advances in Archaeological Method and Theory, Vol. 5, Academic Press, New York, 1982. pp. 275-330.

Статья подготовлена при поддержке гранта РФФИ, проект 13-06-12057-офи-м.

\section{PETROGRAPHY FOR ASSESSMENT OF MOULDING COMPOUND OF ANCIENT POTTERY}

(C)2015

M.A. Kulkova, candidate of geological and mineralogical sciences, associate professor of the department of «Geology and geoecology»

Herzen State University, St.Petersburg (Russia)

Annotation. Ancient ceramics are the valuable artifacts which saves the information about ancient people and their traditions. The process of making pottery is begun with the choosing and preparation of raw clay and temper material and further applying of different techniques (moulding of vessel, decoration etc.) and finally firing. Petrographical analysis of ancient pottery allows to determine the mineralogical composition of ceramic matrix, the features of their technology and to identify the raw mineral sources (Feliu et al. 2004, Papadopoulou et al. 2006, Bastie et al. 2006). Such kind investigations expand the frames of our knowledge about ancient technological traditions in pottery making. The following characteristics could be determined in thin-sections of ceramic shards: nature and features of plastic and aplastic inclusions; textural and optical characteristics of clay matrix; shape, amount and orientation of pores; features of surface treatment, decoration. This information is an 
important for understanding of principles of ancient technologies. The different temper materials inside clay matrix such as sand, crushed rocks, organic materials, shells, grog can be identified accurately using petrography. The ceramic structure and characteristics of mineral changes during the firing are indicators of firing temperatures and atmosphere. A distribution of clay particles and porous inside of ceramic matrix is useful for reconstruction of moulding methods. The study of ceramic collection of the same cultural tradition and from the same region using petrography gives the possibility for differentiation of the natural and cultural factors influenced on the choose of raw materials, variations in the ceramic composition and techniques. This method is one the most precise for identification of an import pottery.

Keywords: petrography; ancient ceramics; grog; temper; raw sources; moulding compound of ancient pottery.

\title{
УДК 902 \\ К ИЗУЧЕНИЮ ПРИЕМОВ НАНЕСЕНИЯ «ТЕКСТИЛЬНЫХ» ОТПЕЧАТКОВ НА КЕРАМИКЕ ДЬЯКОВСКОЙ КУЛЬТУРЫ
}

(C) 2015

\author{
O.A.Лопатина, младший научный сотрудник отдела теории и методики \\ Институт археологии РАН, Москва (Россия)
}

\begin{abstract}
Аннотация. В статье изложены результаты реконструкции приемов и инструментов, с помощью которых на поверхности сосудов дьяковской культуры возникали «текстильные» отпечатки.

К появлению подобных отпечатков могли приводить следующие приемы: 1) конструирование внутри рельефной формы-емкости, 2) выбивание колотушкой с рельефной поверхностью, 3) прокатывание рельефным валиком, 4) штампование.

Данные эксперимента позволили доказать, что текстильные отпечатки являлись в основном результатом прокатывания рельефным штампом.

Специальное исследование позволило установить специфические признаки прокатывания на примере керамики с так называемыми «ниточными» отпечатками. Были выявлены различия в следах, оставленных сходными инструментами - валиком обмотанным нитями и плоской колотушкой, обмотанной нитями.

Прием прокатывания выявлен в отношении еще одной группы керамики - «рябчатой». Также реконструирован инструмент, с помощью которого подобные отпечатки наносились. Это шишки ели с частично удаленными чешуями. Чешуи шишек могли специально удаляться человеком или быть объеденными мышевидными грызунами. Специфика следов частично удаленных чешуй заключается в особых очертаниях края чешуй, отпечатках волокон, следов зубов мышевидных грызунов, отпечатках продольного ребра чешуй.

Массовость рассмотренных отпечатков позволяет говорить о существовании определенной культурной традиции в среде дьяковского гончарства.
\end{abstract}

Ключевые слова: дьяковская культура; текстильная керамика; эксперимент; прокатывание; реконструкция; орнаментиры.

Наличие «текстильных» отпечатков на поверхности керамики железного века традиционно рассматривается в археологической литературе как аргумент для заключений о культурной принадлежности памятников, их хронологии, а также об этносе населения. Вместе с тем, приемы нанесения отпечатков, связанные с особенностями гончарных традиций, изучены слабо. Исследование культурных традиций в гончарстве, передающихся по наследству через навыки труда гончаров, могли бы дать обоснованные данные о характере взаимодействия разных групп древнего населения, о его однородности или неоднородности [1].

В данной статье изложены результаты реконструкции приемов и инструментов, с помощью которых на поверхности сосудов дьяковской культуры возникали «текстильные» отпечатки.

Морфологически «текстильные» отпечатки на дьяковской керамике очень разнообразны. В настоящее время ряд исследователей разделяет их по особен- ностям морфологии на «ниточные» и «рябчатые» [2, с. $379 ; 3$, с. $205 ; 4$, с. $110-111 ; 5$, с. 147-148]. «Ниточные» достаточно стандартны и представляют собой отпечатки нитей или точнее тонких веревочек, различающихся по толщине, особенностям скручивания, и, вероятно, материалов, из которых они изготовлены. Под термином «рябчатые» принято объединять следы в виде отдельных элементов-ячеек различных форм и пропорций, покрывающих всю поверхность сосуда (рис. 1).

Предложенный А.А.Бобринским подход к изучению гончарного производства как системного образования, обладающего определенный структурой [6, c. 8, 9], позволил четко представить себе возможный набор узких технологических задач и приемов их осуществления, которые могли приводить к появлению «текстильных» отпечатков на поверхности сосудов. Эти приемы следующие.

Во-первых, конструирование внутри рельефной формы-емкости, в процессе которого решалась задача 